\title{
Memoria de una experiencia docente
}

\section{Dr. Álvaro Matute*}

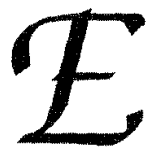

1 primer acto público académico que realicé como Director de este Centro de Enseñanza para Extranjeros fue, precisamente, la celebración de los 60 años de historia del CEPE y estar aquí ahora, en la celebración de su 80 aniversario, me hace conciente de que han pasado ya 20 años, razón por la cual tal vez mi júbilo se sienta limitado; pero en realidad estoy muy contento de estar aquí hoy, en compañía de quienes, al igual que yo, hemos compartido la grata responsabilidad de estar al frente del Centro de Enseñanza para Extranjeros.

Creo que tendría unos cinco años de experiencia docente cuando José Luis Balcárcel (aquí presente, por cierto) me invitó a impartir la clase "Revolución mexicana", para los cursos de 1972, mismo que repetí para 1973. Por esos años se gestaba el primer empuje, muy fuerte, de lo que llamamos "la historiografía revisionista de la Revolución Mexicana", ¿qué quiere decir esto? Pues que un grupo de jóvenes de mi generación, empezaba a producir nuevos conceptos, nuevos libros con nuevas actitudes analíticas, de actitudes críticas respecto a la Revolución Mexicana; entre ellas tuvo mucho impacto el libro de John Womack sobre Emiliano Zapata; apareció por esos años también el primer tomo de La cristiada, de Jean Meyer, $y$ nuestro buen amigo y colega Arnaldo Córdoba estaba dando a conocer la ideología de la Revolución Mexicana en un libro que tuve el privilegio de leerlo ien mimeógrafo! Los más jóvenes dirán "¿y eso qué es?" Aquí me doy cuenta otra vez de que ha pasado el tiempo.

Las lecturas y la enseñanza que iniciábamos por entonces, tendía a establecer nuevas ideas

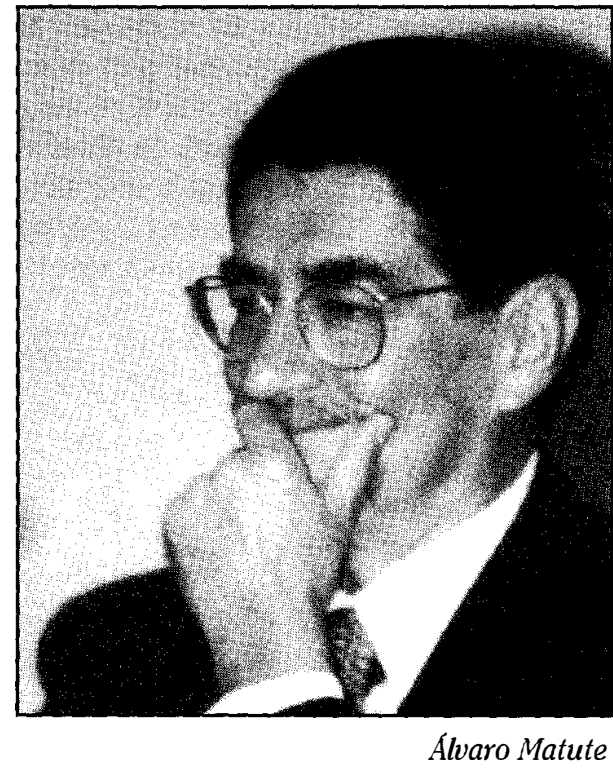

respecto a la enseñanza de la historia de nuestro movimiento reovolucionario que abandonaba, por un lado, el sentimiento épico: ver a la Revolución como epopeya, no, nosotros la veíamos como un proceso histórico y buscábamos, sobre todo, dejar en claro todos los matices ideológicos de los diferentes grupos que participaron en ella; vincularlos con sus actores sociales; referirnos a los planes políticos, a las ideas influyentes y cómo todo esto se cristaliza en la reconstitución del estado mexicano, como consecuencia de la experiencia revolucionaria, es decir, nos interesaban otros conceptos.

Con este bagaje y este escenario académico, pues, me enfrenté a dos generaciones de alumnos del CEPE, en dos veranos consecutivos. Más tarde, cuando fui director entre 1981 y 1984 ,

*Director del CEPE 1981-1984 
volví a la carga docente - que es uno de mis vicios consuetudinarios - y entonces me adjudiqué no ya clases en los veranos porque eran diarias y la oficina no me permitía atender los grupos, así es que tomé clases "terciadas", es decir, cursos intensivos de dos clases por semana y enseñé de nuevo "Revolución mexicana", aunque también tuve el acto inconsciente de darle clase en inglés a un grupo especial de profesores de la Universidad de Mississippi; se trataba de una introducción a la demografía histórica de México. Esa hazaña de dar clases en inglés no lo hago con frecuencia, pero esa primera experiencia me permitió relajarme como docente $y$ ampliar mis horizontes académicos.

El primer grupo que tuve aquí en el CEPE lo recuerdo borrosamente: deben haber sido estudiantes estadounidenses del nivel college (licenciatura), seguramente algunos del junior year board (recién ingresados), estudiantes

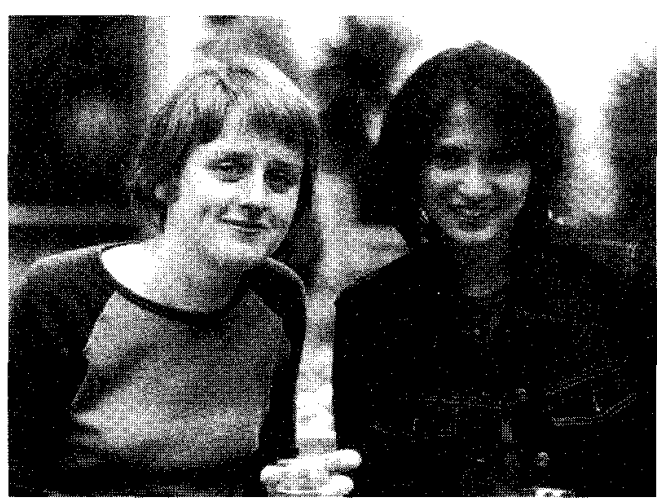

Estudiantes del CEPE rianos mexicanos, no tiene uno que sacar el mapa para decirles dónde está Apatzingán o cualquier cosa: no saben dónde está el norte, dónde está el sur, dónde está Yucatán, Sonora, etcétera, cosas que los extranjeros no necesariamente saben, o si medio lo saben les cuesta trabajo fijarlo. Vayamos un momento, pensemos que estamos, digamos, en una universidad florentina recibiendo un curso de historia italiana para extranjeros; yo me tardaría un rato largo en ubicar dónde está Macherata $y$ Lemarque y la Pianura pagana, en fin, toda la geografía italiana pues, tendría que sacar a cada rato mi mapita para ubicarme. Y en cuanto a los tiempos históricos, pasaría algo semejante.

Así pues, lo primero que tiene que hacer uno frente a un grupo de extranjeros es contextualizarlos en lo que les vamos a enseñar para que todo les quede perfectamente claro; realmente estamos dando californianos que abundaban por entonces, estudiantes, digamos: estándar. $\mathrm{Al}$ año siguiente, en cambio, tuve a un grupo integrado exclusivamente por jóvenes chicanos, provenientes todos, o la mayoría, de California, y quienes tenía mucho interés en México, en recuperar sus raíces. Me tocó pues participar en esa experiencia docente. Ya como director el grupo quedó reducido a una pareja muy agradable de estudiantes japoneses a quienes daba clase en la dirección para no ocupar un salón más.

Aquellos primeros grupos carecían totalmente de los referentes histórico-grográficos que tiene el estudiante mexicano. Puedo decirles, con toda seguridad, que es mucho más fácil dar clases en una preparatoria, como lo hice yo cuando empecé, pues por más precaria que sea la enseñanza que hayan recibido los preparato- dos niveles de enseñanza a un mismo tiempo, lo cual es una práctica docente realmente muy fina, muy importante, que quien logra dominarla merece todos los reconocimientos porque resulta difícil. Algo ayuda que haya cierta homogeneidad en los grupos, que sean la mayoría de una misma nacionalidad; en cambio, cuando las nacionalidades son diversas, los referentes tienen que ser diversos necesariamente.

Hay otras experiencias académicas que me gustaría rescatar del ejemplo de mi clase de "Revolución Mexicana". Comentaba que estábamos en proceso de reelaboración histórica de nuestro movimiento armado de principios del siglo Xx; nos sentíamos casi depositarios de la verdad histórica frente a las generaciones anteriores cuyos conceptos, como les decía, eran épicos y archipolémicos. Esa historiografía 
